\title{
Janet Vertesi, Seeing Like a Rover: How Robots, Teams, and Images CRaft Knowledge of Mars. Chicago AND LONDON: University OF ChICAgo PRESS, 2015. $318+$ XI PP. ISBN: 978-0-226-15596-8.
}

\author{
José Saraiva \\ Research fellow* \\ CIUHCT, University of Lisbon, Faculty of Sciences.
}

In 2004, two identical NASA rovers were deployed on the surface of Mars. Eleven years later, one of them is still functional. The mission is considered an unabated success, as both rovers gathered conclusive evidence that liquid water played a role in the evolution of the Martian landscape. Those rovers were part of an intensive program for the exploration of Mars, involving automated probes collecting data through a myriad of instruments. One thing they have in common: they all acquire images. They all see Mars.

There have been many books about Mars, its geology, the way humans have seen and dreamed the red planet, and the many robotic missions exploring it. This is another book that will undoubtedly appeal to anyone interested in the exploration of the Solar System. But what one will find between its covers is not just a simple narrative of scientific discovery, or of using instruments aboard rovers.

The author, a sociologist and historian of science now at the University

${ }^{*}$ FISCIPE: Field Scientists in Late Portuguese Empire: Knowledge, Ideology, Governance

HoST - History of Science and Technology 10, pp. 129-131 
of Princeton, spent more than two years conducting ethnographic fieldwork, in close contact with a team of geologists, astronomers and engineers. The title chosen, Seeing like a Rover, will surely arouse the attention of people that never gave a thought about the exploration of Mars, given the explicit reference to James C. Scott's Seeing like a State. If the latter spoke of the way centralized states impose certain forms of visualization to achieve authoritarian control over populations and landscapes, in this case the author focuses on how images, and the rules and rituals related to their study, consolidate social relations and thus create consensus. Her main assertion is that the images both represent the surface of Mars, and portray the team that, all things considered, is responsible for their acquisition and significance.

Vertesi follows the images of Mars from their planned acquisition to their calibration, manipulation, discussion and use on communication to the planetary community or release to the public. In each chapter she examines practical activities, from general meetings to focused

discussions and computer processing or production of annotated images. Vertesi shows that Mars images are far from a matter for cold, impartial, objective and indisputable computers. Human visual judgment is needed to compare computers' results with what Mars should look like. And this way of seeing can only be gained through training, experience and collective agreement. Images and the maps produced from them inform new observations, but the different priorities of different expert groups are very often a matter of dissent. Vertesi follows the process of how these observations are proposed, debated, disagreed upon, sometimes conjoined and finally approved. The author also discusses the collective rules that ensure that the digital images worked on by individual team members can be trusted. Vertesi does not forget apparently mundane questions, such as funding or political support for the continuation of the long standing mission. In the frame of American politics, this means a group effort for maintaining high levels of public attention and support, through the production of images that appeal and show what the tax-payers money has achieved.

In every chapter the author emphasizes the general efforts to reach a consensus, the all-around feeling of satisfaction when it is achieved, and that social order is not only kept but reinforced through the renewal of the commitment to the team goals. Throughout the book the author presents several examples of moments of disagreement and shows how technical conflicts were resolved, through the use of rituals and strategies for problem-solving, that turn them into constructive blocks, instead of disruptive experiences.

This book is something of a landmark. Though there have been other 
works that accompany the

practices of teams of scientists, there was never a description of the work of a group of people so far removed from the instruments that provide them with the raw material for their inquiries. The author seems to have captured almost to perfection some particularities of this wok, such as the constant puzzlement before new images, the eagerness to see what will emerge beyond the current horizon.

As it stands, this work shows a never before seen a view of the workings of an enlarged team that follows rules and rituals that strengthen its collective character and lead to the constitution of a "we" entity that includes the very machines that, millions of $\mathrm{km}$ away, acquire the images that make Mars knowable. In the end, however, humans are the ones doing the exploring. 